\title{
ANALISIS EVALUASI PEMBELAJARAN GURU TERSERTIFIKASI DI SMA JAKARTA PUSAT
}

\author{
Samadi $^{1}$, Nuraini ${ }^{2}$ \\ Fakultas Ilmu Sosial \\ Universitas Negeri Jakarta
}

Email:samadi@unj.ac.id

\begin{abstract}
Abstrak
The purpose of this study was to analyze aspects of the evaluation of learning in high school schools in Central Jakarta. The method used in this research is quantitative descriptive through the analysis of learning tools used in daily teaching and learning activities. The sample of this study consisted of 19 geography teachers who had been certified at SMAN 25, SMAN 4, and SMAN 68, SMAN 35, SMAN 7, SMAN 24, SMAN 30, SMAN 5, SMAN 1, and SMAN 10, and private schools namely SMA Santa Theresia, Paskalis High School, Taman Madya 1 and 5 High School, and Petojo IPPI High School. The analysis technique in this study uses descriptive methods in the form of matrix analysis. The results of the study indicate that the teacher learning tools that have been certified, especially in the evaluation component of learning are as follows: (1) Not the work of the teacher itself, namely the results of giving or the effects of selecting specifically for teaching materials and student worksheets, and (2) Not fully developed.
\end{abstract}

Keywords: Learning evaluation analysis, Certified teacher, Central Jakarta High School

\begin{abstract}
Abstrak
Tujuan penelitian ini adalah menganalisis aspek-aspe evaluasi pembelajaran di sekolah-sekolah SMA di Jakarta Pusat. Metode yang digunakan dalam penelitian ini adalah deskriptif kuantitatif melalui analisis perangkat pembelajaran yang digunakan dalam kegiatan belajar mengajar sehari-hari. Sampel penelitian ini terdiri dari 19 orang guru geografi yang telah disertifikasi di SMAN 25, SMAN 4, dan SMAN 68, SMAN 35, SMAN 7, SMAN 24, SMAN 30, SMAN 5, SMAN 1, dan SMAN 10, serta sekolah swasta yaitu SMA Santa Theresia, SMA Paskalis, SMA Taman Madya 1 dan 5, dan SMA IPPI Petojo. Teknik analisis dalam penelitian ini menggunakan metode deskriptif dalam bentuk analisis matriks. Hasil penelitian menunjukkan bahwa perangkat pembelajaran guru yang sudah disertifikasi khususnya pada komponen evaluasi pembelajaran adalah sebagai berikut : (1) Bukan hasil karya guru itu sendiri, yaitu hasil pemberian atau hasil dari memilih khusus untuk bahan ajar dan lembar kerja siswa, serta (2) Tidak dikembangkan secara maksimal.
\end{abstract}

Kata kunci : Analisis evaluasi pembelajaran, Guru tersertifikasi, SMA Jakarta Pusat

\section{PENDAHULUAN}

Tuntutan dari Pasal 42 UU RI

No.20 Tahun 2003 tentang kualifikasi

minimum seorang guru yang dipertegas dalam Pasal 28 Ayat 1 PP RI No.14

Tahun 2005 tentang kualifikasi

akademik minimal; merupakan daya

ledak kuat bagi peningkatan kompetensi 
guru sebagai agen pembelajaran yaitu kompetensi kepribadian, pedagogis, profesional, dan sosial. Kompetensi kepribadian merupakan kompetensi yang menyangkut dengan kepribadian seorang guru. Kompetensi pedagogis adalah kompe-tensi yang berkaitan dengan kemampuan mengelola pembelajaran. Kompetensi profesional berkaitan dengan penguasaan materi pelajaran secara luas dan mendalam. Sedangkan kompetensi sosial berkaitan dengan kemampuan guru untuk berkomunikasi dan berinteraksi dengan seluruh elemen sekolah. Keempat elemen kompetensi ini mustrinya sudah terukur dalam sebuah system sertifikasi guru berdasarkan dua ketentuan di atas.

Berdasarkan Masnur Muslich (2007:1-2), sertifikasi adalah proses pemberian sertifikat pendidik kepada guru yang telah memenuhi persyaratan tertentu, yaitu memiliki kualifikasi akademik, kompetensi, sehat jasmani dan rohani, serta memiliki kemampuan untuk mewujudkan tujuan pendidikan nasional, yang dibarengi dengan peningkatan kesejahteraan yang layak. Merujuk pada ketentuan Pasal 42 ayat (1) UU Sisdiknas yang terdapat (Trianto dan Tutik, 2007:11), dalam sertifikasi harus sesuai dengan jenjang kewenangan mengajar, sehat jasmani dan rohani, serta memiliki kemampuan untuk mewujudkan tujuan pendidikan nasional. Istilah sertifikasi dalam makna kamus berarti surat keterangan (sertifikat) dari lembaga berwenang yang diberikan kepada jenis profesi dan sekaligus pernyataan (lisensi) terhadap kelayakan profesi untuk melaksanakan tugas. Sertifikasi secara yuridis menurut ketentuan Pasal 1 ayat (11) UUGD adalah proses pemberian sertifikasi pendidik untuk guru atau dosen. Adapun berkaitan dengan sertifikasi guru, dijelaskan dalam Pasal 1 ayat (7), bahwa sertifikasi adalah proses pemberian sertifikat pendidik untuk guru. Dasar hukum tentang perlunya sertifikasi guru dinyatakan dalam Pasal 8 Undang-Undang Nomor 14 Tahun 2004 tentang guru dan dosen, bahwa guru dan dosen harus memiliki kualifikasi akademik, kompetensi, sertifikat pendidik, sehat jasmani dan rohani, serta memiliki kemampuan untuk mewujudkan tujuan pendidikan nasional secara profesional. Istilah profesional oleh Buchari Alma, dkk (2009:133-134) diartikan sebagai pekerjaan yang aktivitas pelatihan dan penguasaan 
pengetahuannya dinaungi oleh sebuah asosiasi profesi, kode etik dan proses sertifikasi serta izin atau lisensi resmi. Istilah profesi juga diartikan sebagai suatu pekerjaan yang memiliki karakteristik adanya praktek yang ditunjang dengan teori, pelatihan, kode etik yang mengatur perilaku, dan punya otonomi yang tinggi dalam pelaksanaan pekerjaannya.

Sertifikasi guru berdasarkan dua ketentuan undang-undang dan peraturan pemerintah di atas mensyaratkan adanya perbaikan kualitas pengajaran bagi guru dari beberapa aspek, salah satunya adalah perangkat pembelajaran. Perangkat pembelajaran terdiri dari silabus, rencana pelaksanaan pembelajaran (RPP), media pembelajaran, bahan ajar, lembar kegiatan siswa, dan evaluasi pembelajaran. Dalam tulisan ini, variabel evaluasi pembelajaran dianalisis secara mendalam guna mengetahui manfaat dan pengaruh sertifikasi guru di dalam upaya peningkatan profesionalisme guru khususnya dalam mata pelajaran geografi di sekolah di Jakarta Pusat. Evaluasi pembelajaran dalam konteks ini merupakan rangkaian kegiatan penilaian hasil belajar siswa.

Kunandar (2007:383-385) juga oleh Wand dan Gerald W.Brown (1977); evaluasi adalah suatu tindakan atau suatu proses untuk menentukan suatu nilai keberhasilan belajar peserta didik setelah ia mengalami proses belajar selama satu periode tertentu. Evaluasi juga dapat diartikan kegiatan yang terencana untuk mengetahui keadaan sesuatu objek dengan menggunakan instrumen dan hasilnya dibandingkan dengan tolak ukur untuk memperoleh kesimpulan. Evaluasi bukan sekedar menilai suatu aktivitas secara spontan dan insidental, melainkan merupakan kegiatan untuk menilai sesuatu secara terencana, sistematik, dan terarah beradasarkan atas tujuan yang jelas.

Evaluasi hasil belajar bertujuan untuk mengetahui tercapai tidaknya kompetensi dasar yang telah ditetapkan. Dengan kompetensi dasar ini dapat diketahui tingkat penguasaan materi standar oleh peserta didik, baik yang menyangkut aspek intelektual, sosial, emosional, spiritual, kreativitas, dan moral. Evaluasi dapat dilakukan terhadap program, proses, dan hasil 
belajar. Evaluasi program bertujuan untuk menilai efektivitas program yang dilaksanakan. Evaluasi proses bertujuan untuk mengetahui aktivitas dan pastisipasi peserta didik dalam pembelajaran. Evaluasi hasil belajar bertujuan untuk mengetahui hasil belajar atau pembentukan kompetensi peserta didik. Evaluasi hasil belajar dilakukan dengan penilaian kelas, dan penilaian akhir satuan pendidikan dan sertifikasi. Penilaian pendidikan pada jenjang pendidikan dasar dan menengah atas terdiri atas penilaian hasil belajar oleh pendidik, penilaian hasil belajar oleh satuan pendidikan, serta penilaian hasil belajar oleh pemerintah (PP 19/2005).

Disisi lain, program evaluasi yang baik dapat diketahui dari ciri-ciri (M. Ngalim Purwanto, 1984:17-19) antara lain : (1) Design atau rancangan program evaluasi itu komprehensif; tujuan-tujuan umum yang akan dinilai hendaknya mencakup tidak hanya keterampilan, dan pengetahuan tetapi juga apresiasi, sikap, minat, pemikiran kritis, dan penyesuaian diri yang bersifat personal dan sosial. Suatu design evaluasi dikatakan komprehensif jika ia mencakup nilainilai dan tujuan-tujuan pokok yang akan dicapai oleh sekolah itu bagi setiap individu murid. (2) Perubahanperubahan tingkah laku individu harus mendasari penilaian pertumbuhan dan perkem-bangannya; tingkah laku total individu-intelektual, fisik, emosional, dan sosial harus menjadi perhatian guru dan supervisor di dalam setiap situasi belajar. Hal ini ditujukan agar guru dapat melihat perubahan-perubahan sikap yang terjadi pada peserta didik dan bisa melakukan antisipasi terhadap sikapsikap yang akan muncul ketika proses belajar mengajar. (3) Hasil-hasil evaluasi harus disusun dan dikelompokkelompokkan sedemikian rupa sehingga memudahkan interpretasi yang berarti; hasil-hasil kuantitatif dan kualitatif yang diperoleh dari program evaluasi harus disimpulkan ke dalam pola penskoran yang jelas, secara statistik, grafik, ataupun secara verbal, sehingga dari data evaluasi itu gambaran atau lukisan individu dapat dilihat dan dipahami dengan mudah, dan dapat dibandingkan dengan keadaan sebelum-nya. Dengan demikian dapat dilihat kemana arah perkembangan individu tersebut. (4) Program evaluasi haruslah berkesinambungan dan saling berkaitan (interrelated) dengan kurikulum; suatu 
program evaluasi haruslah erat berkaitan (interrelated) dengan kurikulum sekolah karena ia merupakan bagian yang integral dengan pembimbingan pengalaman-pengalaman belajar siswa. Tes, kuisioner, dan alat-alat evaluasi yang lain bersama-sama merupakan dasar untuk menilai pertumbuhan ke arah tujuan-tujuan kurikulum. Dengan kata lain, tercapai tidaknya tujuan-tujuan kurikulum itu tercermin dalam hasilhasil penilaian terhadap pencapaian belajar dan perubahan-perubahan tingkah laku siswa.

\section{METODOLOGI PENELITIAN}

Tujuan penelitian ini adalah untuk menganalisis perangkat pembelajaran guru yang telah disertifikasi khususnya pada aspek evaluasi pembelajaran di sekolah-sekolah SMA di Jakarta Pusat. Metode yang digunakan dalam penelitian ini adalah deskriptif kuantitatif melalui analisis perangkat pembelajaran yang digunakan dalam kegiatan belajar mengajar sehari-hari. Sampel penelitian ini terdiri dari 19 orang guru geografi yang telah disertifikasi di SMAN 25, SMAN 4, dan
SMAN 68, SMAN 35, SMAN 7, SMAN 24, SMAN 30, SMAN 5, SMAN 1, dan SMAN 10, serta sekolah swasta yaitu SMA Santa Theresia, SMA Paskalis, SMA Taman Madya 1 dan 5, dan SMA IPPI Petojo. Adapun teknik pengumpulan data melalui data primer yang berasal pada data daftar checklist dengan pihak terkait, serta data sekunder dari hasil survei, informasi dari Suku Dinas Pendidikan Jakarta Pusat dan studi literatur. Konten data penelitian memiliki aspek-aspek komprehensif, kesinam-bungan, obyektivitas, kemajuan yang dicapai oleh peserta didik, serta adanya lembar pelaporan hasil evaluasi dan penilaian sekurang-kurangnya setiap akhir semester yang ditujukan kepada kepala sekolah / madrasah dan orang tua/ wali peserta didik. Teknis analisis dalam penelitian ini menggunakan metode deskriptif dalam bentuk analisis matriks.

\section{HASIL DAN PEMBAHASAN}

Hasil tabulasi pengukuran pembelajaran dapat diuraikan sebagai berikut : 


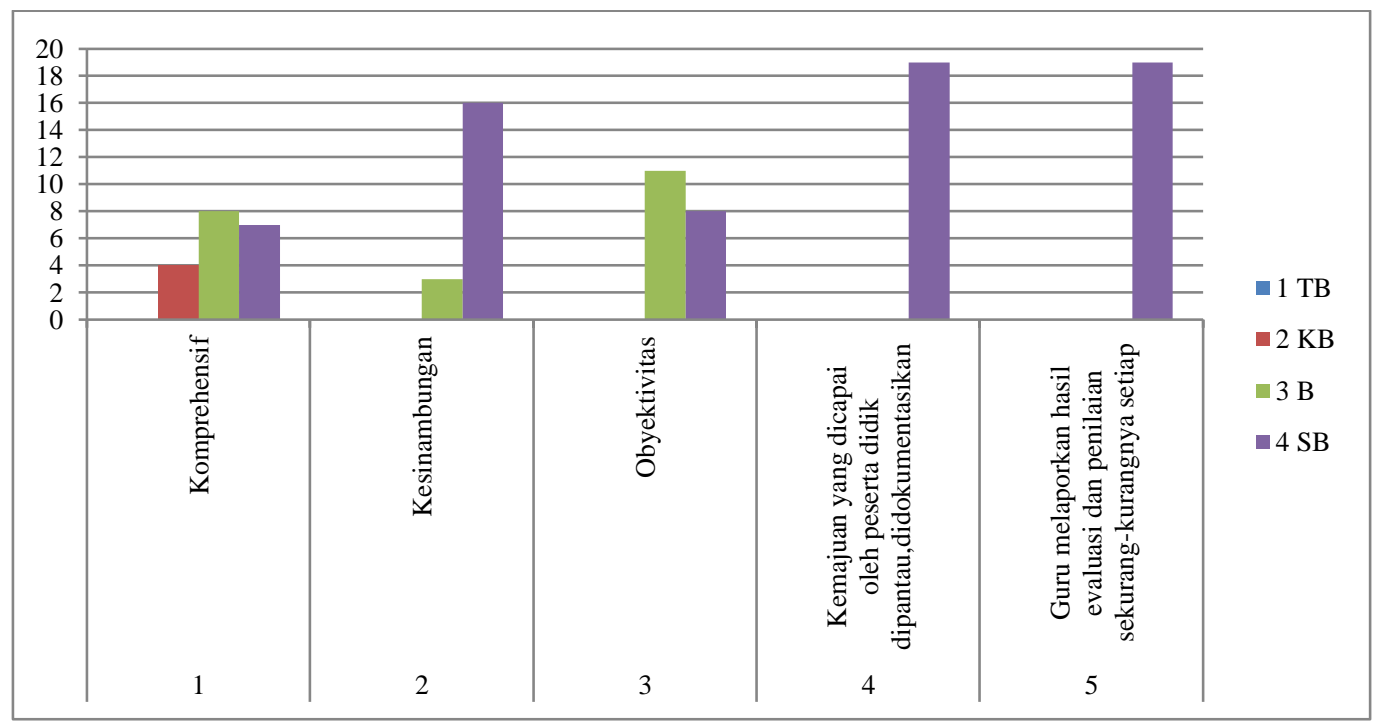

\section{Grafik 1. Tabulasi pengukuran pembelajaran}

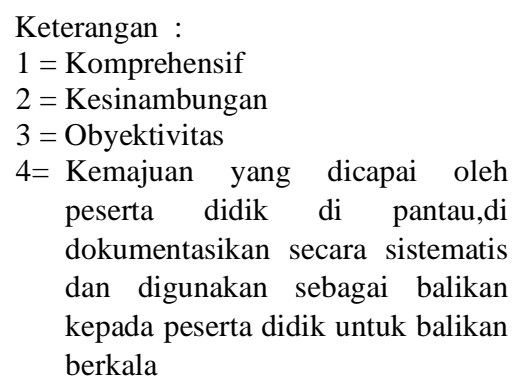
dokumentasikan secara sistematis dan digunakan sebagai balikan kepada peserta didik untuk balikan berkala

a. Komprehensif. Untuk standar pengukuran ini terdapat 5 orang guru dengan nilai kurang baik,8 orang guru baik dan 7 orang guru dengan nilai sangat baik.Guru-guru yang mendapatkan nilai kurang baik adalah guru-guru di sekolah G1, K, L1, dan L2. Sedangkan guru-guru yang mendapatkan nilai baik adalah guru-guru di sekolah A, E, F, G2, I1, J, M, dan N.Untuk guru-guru di sekolah B, C1, C2, D, H, I2, dan O mendapatkan nilai sangat baik.

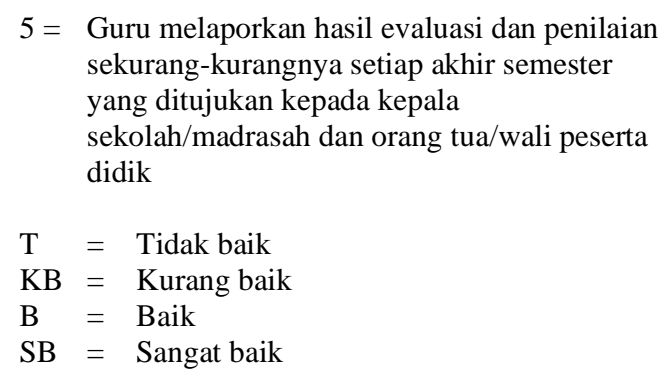
sekurang-kurangnya setiap akhir semester yang ditujukan kepada kepala sekolah/madrasah dan orang tua/wali peserta didik

$\mathrm{T}=$ Tidak baik

$\mathrm{KB}=$ Kurang baik

$\mathrm{B}=$ Baik

$\mathrm{SB}=$ Sangat baik

b. Kesinambungan. Untuk standar pengukuran ini terdapat 3 orang guru dengan nilai baik dan 16 orang guru dengan nilai sangat baik. Guru-guru yang mendapatkan nilai baik adalah guru-guru di sekolah $\mathrm{E}, \mathrm{J}$, dan $\mathrm{N}$. Sedangkan guru-guru yang mendapatkan nilai sangat baik adalah guru-guru di sekolah A, B, C1, C2, D, F, G1, G2, H, I1, I2, K, L1, L2, $\mathrm{M}$, dan $\mathrm{O}$.

c. Obyektivitas. Untuk standar pengukuran ini terdapat 11 orang guru dengan nilai baik dan 8 orang 
guru dengan nilai sangat baik. Guruguru yang mendapatkan nilai baik adalah guru-guru di sekolah A, E, F, G1, H, I1, I2, J, L1, M, dan N. Sedangkan guru-guru yang mendapatkan nilai sangat baik adalah guru-guru di sekolah B, C1, C2, D, G2, K, L2, dan O.

d. Kemajuan yang dicapai oleh peserta didik dipantau, didokumentasikan secara sistematis, dan digunakan sebagai balikan kepada peserta didik untuk perbaikan secara berkala.
Untuk standar pengukuran ini semua guru memperoleh nilai sangat baik. Dari sekolah A hingga sekolah O memperoleh nilai sangat baik.

e. Guru melaporkan hasil evaluasi dan penilaian sekurang-kurangnya setiap akhir semester yang ditujukan kepada kepala sekolah/madrasah dan orang tua / wali peserta didik. Untuk standar pengukuran ini semua guru mendapatkan nilai sangat baik. Dari sekolah A hingga sekolah $\mathrm{O}$ memperoleh nilai sangat baik.

\section{Tabel 1. Matriks Evaluasi Pembelajaran}

\begin{tabular}{llllll}
\hline Nama & \multicolumn{5}{c}{ Variabel Pengukuran Evaluasi Pembelajaran } \\
\cline { 2 - 6 } Sekolah & 1 & 2 & 3 & 4 & 5 \\
\hline Sekolah A & 3 & 4 & 3 & 4 & 4 \\
Sekolah B & 4 & 4 & 4 & 4 & 4 \\
Sekolah C & 4 & 4 & 4 & 4 & 4 \\
Sekolah C & 4 & 4 & 4 & 4 & 4 \\
Sekolah D & 4 & 4 & 4 & 4 & 4 \\
Sekolah E & 3 & 3 & 3 & 4 & 4 \\
Sekolah F & 3 & 4 & 3 & 4 & 4 \\
Sekolah G & 2 & 4 & 3 & 4 & 4 \\
Sekolah G & 3 & 4 & 4 & 4 & 4 \\
Sekolah H & 4 & 4 & 3 & 4 & 4 \\
Sekolah I & 3 & 4 & 3 & 4 & 4 \\
Sekolah I & 4 & 4 & 3 & 4 & 4 \\
Sekolah J & 3 & 3 & 3 & 4 & 4 \\
Sekolah K & 2 & 4 & 4 & 4 & 4 \\
Sekolah L & 2 & 4 & 3 & 4 & 4 \\
Sekolah L & 2 & 4 & 4 & 4 & 4 \\
Sekolah M & 3 & 4 & 3 & 4 & 4 \\
Sekolah N & 3 & 3 & 3 & 4 & 4 \\
Sekolah O & 4 & 4 & 4 & 4 & 4 \\
\hline & & & & & \\
\hline
\end{tabular}


Keterangan Tabel :

$1=$ Komprehensif

$2=$ Kesinambungan

3 = Obyektivitas

4 = Kemajuan yang dicapai oleh peserta didik di pantau,di dokumentasikan secara sistematis dan digunakan sebagai balikan kepada

Dalam kegiatan evaluasi pembelajaran yang ada, semua sekolah melakukan kegiatan evaluasi yang sama yaitu berbentuk tes tertulis. Tes tertulis ini disebut ulangan. Biasanya ulangan yang dilakukan ada 4 tahap yaitu ulangan harian bersama,ujian tengah semester dan ujian akhir semester. Untuk ulangan harian biasanya dilakukan tergantung pada setiap mata pelajaran masing-masing.Untuk hasil balikan yang diberikan kepada peserta didik berupa rapor yang berisi hasil dari belajar siswa yang berupa angka dan sikap sehari-hari peserta didik. Rapor pun terdiri dari 4 bagian yaitu rapor bayangan 1, rapor semester 1 , rapor bayangan 2 , dan rapor semester 2 (kenaikan kelas).

Dalam 5 variabel dalam tabel matriks diatas terdapat hasil yang seragam terutama dalam variabel 4 dan 5 hal ini dikarenakan semua sekolah melakukan system evaluasi yang sama seperti pada penjelasan di awal paragraf. Oleh karena itu pada kedua variabel

\author{
peserta didik untuk balikan \\ berkala \\ 5 = Guru melaporkan hasil evaluasi dan \\ penilaian sekurang-kurangnya setiap \\ akhir semester yang ditujukan kepada \\ kepala sekolah/madrasah dan orang \\ tua/wali peserta didik
}

tersebut didapatkan nilai sangat baik yang berarti bahwa setiap evaluasi yang diadakan di sekolah didokumentasikan dengan baik dan dikembalikan kepada orang tua / wali agar dapat mengetahui hasil belajar peserta didik. Khusus untuk peserta didik hal ini dimaksudkan agar lebih rajin lagi belajar dan menjadi motivasi untuk terus belajar.

Sementara itu untuk variabel 1 sampai 3 akan dijabarkan melalui uraian di bawah ini :

1) Sekolah A variabel 2 mendapatkan nilai sangat baik karena proses evaluasi benar-benar dilakukan secara berkelanjutan. Variabel 1 dan 3 mendapatkan nilai baik karena teknik evaluasi kurang menyeluruh hanya berpusat pada kognitif dan afektif sedangkan psikomotor kurang begitu banyak dan evaluasi mulai terlepas dari hal-hal yang bersifat subjektif.

2) Sekolah B variabel 1-3 mendapatkan nilai sangat baik karena proses 
evaluasi benar-benar dilakukan secara berkelanjutan, teknik evaluasi menyeluruh pada aspek kognitif, psikomotorik dan afektif dan evaluasi terlepas dari hal-hal yang bersifat subjektif.

3) Sekolah $C$ terdiri dari 2 orang guru yaitu $\mathrm{C} 1$ dan $\mathrm{C} 2$. Kedua variabel ini memiliki kesamaan nilai yaitu sangat baik dikesemua aspeknya karena proses evaluasi benar-benar dilakukan secara berkelanjutan, teknik evaluasi menyeluruh pada aspek kognitif, psikomotorik dan afektif dan evaluasi terlepas dari halhal yang bersifat subjektif.

4) Sekolah $D$ dalam semua variabel memperoleh nilai sangat baik karena proses evaluasi benar-benar dilakukan secara berkelanjutan, teknik evaluasi menyeluruh pada aspek kognitif, psikomotorik dan afektif dan evaluasi terlepas dari halhal yang bersifat subjektif.

5) Sekolah E dalam semua variabelnya memperoleh nilai baik karena teknik evaluasi kurang menyeluruh hanya berpusat pada kognitif dan afektif sedangkan psikomotor kurang begitu banyak, proses evaluasi mulai dilakukan secara berkelanjutan dan evaluasi mulai terlepas dari hal-hal yang bersifat subjektif.

6) Sekolah $F$ dalam variabel 2 mendapatkan nilai sangat baik karena proses evaluasi benar-benar dilakukan secara berkelanjutan. Variabel 1 dan 3 mendapatkan nilai baik karena teknik evaluasi kurang menyeluruh hanya berpusat pada kognitif dan afektif sedangkan psikomotor kurang begitu banyak dan evaluasi mulai terlepas dari halhal yang bersifat subjektif.

7) Sekolah G terdiri dari 2 orang guru yaitu G1 dan G2. Terjadi perbedaan penilaian diantara komponenkomponen yang ada. Variabel 2 pada G1 mendapatkan nilai sangat baik karena proses evaluasi diadakan secara berkelanjutan dan dipantau terus menerus. Variabel 3 mendapatkan nilai baik karena evaluasi mulai terlepas dari hal-hal yang bersifat subjektif. Variabel 1 mendapatkan nilai kurang baik karena teknik evaluasi lebih menitik beratkan hanya pada aspek kognitif saja. Variabel 2 dan 3 pada G2 mendapatkan nilai sangat baik karena evaluasi diadakan secara berkelanjutan dan evaluasi terlepas 
dari hal-hal yang bersifat subjektif. Variabel 1 mendapatkan nilai baik karena teknik evaluasi kurang menyeluruh hanya berpusat pada kognitif dan afektif sedangkan psikomotor kurang begitu banyak.

8) Sekolah $\mathrm{H}$ dalam variabel 1 dan 2 mendapatkan nilai sangat baik karena teknik evaluasi menyeluruh pada aspek kognitif, psikomotorik dan afektif dan proses evaluasi benar-benar dilakukan secara berkelanjutan. Sedangkan variabel 3 mendapatkan nilai baik karena evaluasi mulai terlepas dari hal-hal yang bersifat subjektif.

9) Sekolah I terdiri dari dua orang guru yaitu I1 dan I2. Terdapat perbedaan penilaian antara I1 dan I2. Variabel 2 pada I1 memperoleh nilai sangat baik karena proses evaluasi sudah berlangsung secara berkelanjutan dan selalu dipantau. Variabel 1 dan 3 pada I1 memperoleh nilai baik karena teknik evaluasi kurang menyeluruh hanya berpusat pada kognitif dan afektif sedangkan psikomotor kurang begitu banyak dan evaluasi mulai terlepas dari halhal yang bersifat subjektif. Variabel 1 dan 2 pada $\mathrm{I} 2$ memperoleh nilai sangat baik karena. Variabel 3 memperoleh nilai baik karena evaluasi mulai terlepas dari hal-hal yang bersifat subjektif.

10) Sekolah J dalam semua variabelnya memperoleh nilai baik karena teknik evaluasi kurang menyeluruh hanya berpusat pada kognitif dan afektif sedangkan psikomotor kurang begitu banyak, proses evaluasi mulai dilakukan secara berkelanjutan dan evaluasi mulai terlepas dari hal-hal yang bersifat subjektif.

11) Sekolah $K$ dalam variabel 2 dan 3 memperoleh nilai sangat baik karena proses evaluasi benar-benar dilakukan secara berkelanjutan, dan evaluasi terlepas dari hal-hal yang bersifat subjektif. Variabel 1 mendapatkan nilai baik karena teknik evaluasi kurang menyeluruh hanya berpusat pada kognitif dan afektif sedangkan psikomotor kurang begitu banyak.

12) Sekolah L terdiri dari dua orang guru yaitu L1 dan L2. Terdapat perbedaan penilaian antara L1 dan L2. Dalam variabel 2 pada L1 memperoleh nilai sangat baik karena proses evaluasi benar-benar dilakukan secara berkelanjutan dan selalu dipantau 
perkembangannya. Variabel 3 memperoleh nilai baik karena evaluasi mulai terlepas dari hal-hal yang bersifat subjektif.Variabel 1 pada L1 dan L2 memperoleh nilai kurang baik karena teknik evaluasi lebih menitik beratkan hanya pada aspek kognitif saja. Variabel 2 dan 3 pada L2 memperoleh nilai sangat baik karena proses evaluasi benarbenar dilakukan secara berkelanjutan, dan evaluasi terlepas dari hal-hal yang bersifat subjektif.

13) Sekolah M dalam variabel 2 mendapatkan nilai sangat baik karena proses evaluasi dilakukan secara berkelanjutan dan hasil terus dipantau.Variabel 1 dan 3 mendapatkan nilai baik karena teknik evaluasi kurang menyeluruh hanya berpusat pada kognitif dan afektif sedangkan psikomotor kurang begitu banyak dan evaluasi mulai terlepas dari halhal yang bersifat subjektif.

14) Sekolah $N$ dalam semua variabelnya memperoleh nilai baik karena teknik evaluasi kurang menyeluruh hanya berpusat pada kognitif dan afektif sedangkan psikomotor kurang begitu banyak, proses evaluasi mulai dilakukan secara berkelanjutan dan evaluasi mulai terlepas dari hal-hal yang bersifat subjektif.

15) Sekolah $O$ variabel 1,2, dan 3 mendapatkan nilai sangat baik karena teknik evaluasi menyeluruh pada aspek kognitif,psikomotorik dan afektif, proses evaluasi benarbenar dilakukan secara berkelanjutan, dan evaluasi terlepas dari hal-hal yang bersifat subjektif.

Proses evaluasi pembelajaran yang dilakukan oleh guru-guru tersebut sudah baik terutama dalam pendokumentasian nilai siswa karna sekarang pemerintah sudah member-lakukan sistem penilaian secara online yang membuat semua guru wajib untuk mendokumentasikan nilai dalam bentuk softcopy maupun hardcopy yang kemudian digunakan juga untuk balikan kepada siswa. Untuk penilaian dalam kegiatan belajar mengajar seharihari pun sudah baik dan menyeluruh. Akan tetapi sistem evaluasi yang ada di sekolah bukan hanya masalah penilaian tetapi juga kelayakan soal yang diujikan. Terdapat kesalahan persepsi penulis dalam proses penelitian sehingga hanya mendapatkan data mengenai sistem penilaian tanpa melihat soal yang digunakan dalam ujian. 
Oleh karenanya, dilakukan proses pengukuran evaluasi pembelajaran dari para guru yang diteliti. Dan hasilnya adalah sebagai berikut :

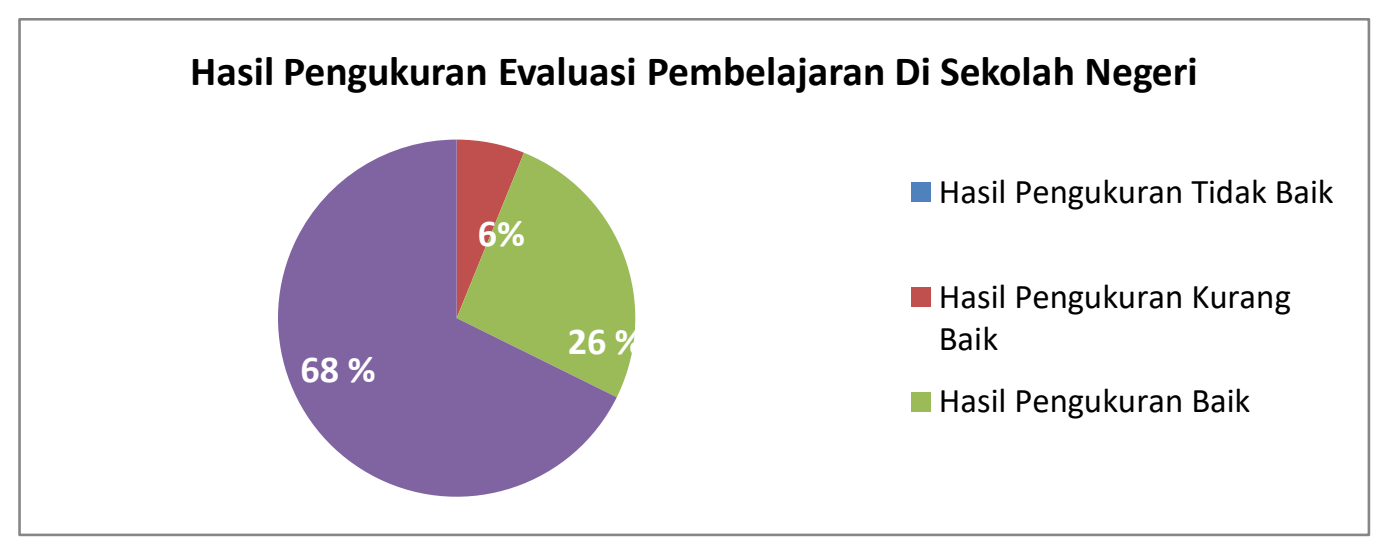

Gambar 2. Diagram Hasil Pengukuran Evaluasi Pembelajaran di Sekolah Negeri

\section{Hasil Pengukuran Evaluasi Pembelajaran Di Sekolah Swasta}

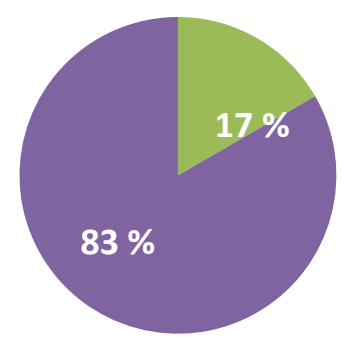

- Hasil Pengukuran Tidak Baik

Hasil Pengukuran Kurang Baik

Hasil Pengukuran Baik

Gambar 3. Diagram Hasil Pengukuran Evaluasi Pembelajaran di Sekolah Swasta 


\section{KESIMPULAN}

Berdasarkan hasil penelitian dapat disimpulkan bahwa perangkat pembelajaran guru yang sudah disertifikasi khususnya pada komponen evaluasi pembelajaran adalah sebagai berikut :

a. Bukan hasil karya guru itu sendiri, yaitu hasil pemberian atau hasil dari memilih khusus untuk bahan ajar dan lembar kerja siswa

b. Tidak dikembangkan secara maksimal

\section{DAFTAR PUSTAKA}

Ahmad Rohani HM. 2004. Pengelolaan

Pengajaran. Jakarta : PT Rineka Cipta.

Azhar Arsyad. 1997. Media Pembelajaran. Jakarta : PT Raja Grafindo Persada.
Buchari Alma,.dkk. 2009. Guru Profesional Menguasai Metode dan Terampil Mengajar. Bandung : Alfabeta.

Kunandar. 2007. Guru Profesional, Implementasi Kurikulum Tingkat Satuan Pendidikan (KTSP) dan Sukses dalam Sertifikasi Guru.Jakarta : Rajagrafindo Persada.

Masnur, Muslich. 2007. Sertifikasi Guru Mепијu Profesionalisme Pendidik. Jakarta : Bumi Aksara.

Moh.Pabundu. 2005. Metode Penelitian Geografi. Jakarta : PT Bumi Aksara.

Trianto dan Titik Triwulan Tutik. 2007. Sertifikasi Guru dan Upaya Peningkatan Kualifikasi, Kompetensi dan Kesejahteraan. Jakarta : Prestasi Pustaka 